\title{
GELANGGANG REMAJA TANJUNG DUREN: SARANA PENYALURAN MINAT DAN BAKAT UNTUK MENINGKATKAN KESEHATAN
}

\author{
Melyna $^{1)}$, Timmy Setiawan ${ }^{21}$
}

1)Program Studi S1 Arsitektur, Fakultas Teknik, Universitas Tarumanagara, melynawijaya@gmail.com

2) Program Studi S1 Arsitektur, Fakultas Teknik, Universitas Tarumanagara, timmy@unitricipta.com

\begin{abstract}
Abstrak
Kesehatan merupakan sebuah aspek fundamental dalam menjalankan kehidupan sehari-hari. Terkhusus pada era milenial kini, generasi milenial akan menjadi generasi yang memiliki tingkat kesehatan yang buruk pada usia pertengahan (lembaga riset Health Foundation). Salah satu factor yang berperan adalah karena, faktanya 93\% millennials tidak melakukan tindakan pencegahan dalam aspek kesehatan. Olahraga merupakan salah satu jalan yang harus ditempuh untuk meraih kesehatan. Menurut Survei Nasional CSIS “Orientasi Sosial, Ekonomi, dan Politik Generasi Milenial 2017, olahraga berada di posisi utama dengan persentase sebesar $30.8 \%$ sebagai kegiatan yang paling menarik minat generasi milenial. Olahraga merupakan sebuah proses yang bersifat sistematis yang dapat berbentuk kegiatan untuk mengembangkan potensi jasmani maupun rohani yang dilakukan oleh beberapa orang atau kelompok. Olahraga merupakan pereda stress yang baik untuk mengalihkan segala pikiran negatif serta untuk peregangan otot (Jessica Dolland, 2004). Juga, merupakan kegiatan untuk melatih tubuh agar segala organ tubuh kita dapat berfungsi secara baik (Suryanto Rukmono S.Si). Adanya potensi terkait kesehatan dengan kegiatan olahraga, khususnya terhadap generasi milenial kemudian menghadirkan potensi untuk menghadirkan sarana dan pra-sarana terkait kegiatan olahraga. Gelanggang remaja merupakan sarana dalam menjalankan kegiatan olahraga yang dinilai sesuai dengan kebutuhan masyarakat khususnya generasi milenial. Tapak yang dipilih berada di Tanjung Duren, yang dikenal sebagai daerah pemukiman padat yang dikelilingi dengan berbagai fasilitas yang cukup lengkap khususnya di bidang pendidikan dan kuliner di Jakarta Barat. Proyek ini bersinergi dengan lingkungan sekitar dalam menciptakan aksesibilitas serta pengadaan ruang bagi public. Program yang dihadirkan berdasarkan pada kebutuhan akan sarana olahraga berupa lapangan olahraga indoor dan outdoor, ruang serbaguna, ruang diskusi, ruang bagi komunitas eSports, serta interactive pool. Proyek diharapkan dapat menjadi sebuah ruang public yang dapat memenuhi kebutuhan masyarakat khususnya pada bidang kesehatan jasmani. Dimulai dengan proses perencanaan yang diawali dengan mengidentifikasi komponen yang menunjang objek (kompleksitas), mengadakan studi untuk mencari keterkaitan berbagai factor yang berpengaruh, mendeterminasi untuk menentukan factor dominan yang berpengaruh terhadap factor lain, serta memprediksi berbagai factor yang ada untuk menjadikan di masa depan lebih baik. Di dalam proses perancangan akan berorientasi kepada pengguna, dimana pengguna menjadi focus utama dalam orientasi. Serta memproyeksikan hingga $>10$ tahun ke depan, berorientasi kepada long-range planning untuk menerapkan konsep arsitektur berkelanjutan. Dalam perjalanannya, antara proses perencanaan dan perancangan akan bersifat interaktif, sehingga merupakan sebuah proses berkelanjutan dengan sistem umpan balik satu dengan yang lain.
\end{abstract}

Kata kunci: gelanggang remaja; kesehatan; olahraga; ruang publik

\begin{abstract}
Health is a fundamental aspect to maintain someone's life. Espescially in this millenial era, millennials would be the generation with a bad health issue in their middle age (Health Foundation research institute). One of the main factor is the fact that 93\% millennials did't do any precaution on their own health. Sports in one thing we could do to achieve a healthy life. According to CSIS National Survey "Social orientation, economic, and politic on millennial generation" on 2017, sports got a number one position with $30.8 \%$ as the most engaging activity for millennials. Sports is a sistematical progress which aim to develop one's physical
\end{abstract}


and spiritual potential which can be done as a group of people / groups. Sports is a great stress-reliever to distract a negative mind as well to stretch body muscles (Jessica Dolland, 2004). Also, is an activity to train our body so that our organs could function well (Suryanto Rukmono S.Si). Health and sports activity then create a potential to answer millennials needs for a sports facility. Youth center is a medium to run a sports activity that's comply to peoples need especially millennials. The chosen site is in Tanjung Duren, which has known as a housing area with a high density surrounded by various facility espescially on food \& beverages and education facility in West Jakarta. This project would have a synergy with it's surroundings, aim to create an accessibility also to provide a public space. The program based on the needs for indoor and outdoor sports court, multifunction room, discussion room, esports community room, and interactive pool. This project aim to become a public space that could cater peoples needs espescially on physical health. Starting with a planning process that begins with identifying the components that support the object (complexity), conducts a study to look for the interrelationships of various influential factors, determines to decide the dominant factors that influence other factors, and predicts the various factors that make the future better. In the design, the process will be user-oriented, where the user becomes the main focus in orientation. As well as projecting up to> 10 years ahead, oriented to long-range planning to apply the concept of sustainable architecture. In its journey, between the planning and design process will be interactive, so that it is an ongoing process with a system of feedback from one to another.

Keywords: health; public space; sports; youth center

\section{PENDAHULUAN}

Kesehatan merupakan sebuah aspek fundamental dalam menjalankan kehidupan seharihari. Terkhusus pada era milenial kini, Generasi milenial akan menjadi generasi yang memiliki tingkat kesehatan yang buruk pada usia pertengahan (lembaga riset Health Foundation). Salah satu factor yang berperan adalah karena, faktanya 93\% millennials tidak melakukan tindakan pencegahan dalam aspek kesehatan, Millennials justru akan memanfaatkan fasilitas kesehatan apabila mereka sudah berada dalam keadaan yang tidak sehat, dalam kegiatan sehari-harinya millennials cenderung memanfaatkan teknologi untuk mengakses berita-berita terkait dengan kesehatan. Namun sejatinya, kesadaran akan kesehatan telah menjadi fokus utama generasi millennials karena faktanya, $40 \%$ generasi milenial telah menjadikan kesehatan sebagai hal yang dianggap paling penting sebagai sumber kebahagiaan (Survei Nasional CSIS “Oritenasi Sosial, Ekonomi, dan Politik Generasi Milenial 2017).

Dalam kaitannya dengan kesehatan, olahraga merupakan salah satu jalan yang harus ditempuh untuk menjaga kesehatan. Menurut Survei Nasional CSIS “Oritenasi Sosial, Ekonomi, dan Politik Generasi Milenial 2017, Olahraga berada di posisi utama dengan persentase sebesar $30.8 \%$ sebagai kegiatan yang paling menarik minat generasi milenial. Olahraga merupakan sebuah proses yang bersifat sistematis yang dapat berbentuk kegiatan untuk mengembangkan potensi jasmani maupun rohani yang dilakukan oleh beberapa orang atau kelompok. Olahraga merupakan pereda stress yang baik untuk mengalihkan segala pikiran negatif serta untuk peregangan otot (Jessica Dolland, 2004). Juga, merupakan kegiatan untuk melatih tubuh agar segala organ tubuh kita dapat berfungsi secara baik (Suryanto Rukmono S.Si).

Kesehatan seseorang meliputi aspek jasmani yaitu kesehatan fisik dan aspek rohani yaitu kesehatan mental. Pada kaitannya dengan aspek kesehatan fisik, Angka kesakitan pada generasi milenial secara keseluruhan di Indonesia pada tahun 2017 sebesar 8,63 persen. Dengan kata lain, terdapat 8 hingga 9 orang dari 100 orang generasi milenial di Indonesia yang mengalami keluhan kesehatan dan aktivitasnya terganggu. Pada kaitannya dengan aspek kesehatan mental generasi milenial, terlebih seiring dengan kemajuan teknologi, generasi milenial cenderung lebih mudah mengalami depresi, psikolog klinis Dr. Fowke mengatakan, krisis quarter life semakin menonjol dalam beberapa tahun terakhir karena tekanan yang dihadapi generasi millennial, jika dibandingkan dengan generasi yang lebih tua. Lebih dari 6 
ribu orang dari Inggris, Amerika Serikat, Australia, dan India diteliti dan ditanyai mengenai hal yang membuat mereka cemas selama usia pertengahan 20an dan awal 30an. Banyak diantaranya yang mengatakan bahwa mereka memiliki kekhawatiran terhadap kariernya. Lalu, sebanyak 59\% dari generasi millennial ini mengatakan mereka tidak yakin apa yang harus dilakukan selanjutnya dalam hidup, $49 \%$ merasa tidak cukup mendapatkan penghasilan, dan $44 \%$ tidak percaya dapat membeli rumah untuk dirinya sendiri.

Adanya potensi terkait kesehatan masyarakat dengan kebutuhan akan ruang untuk melakukan kegiatan berolahraga, khususnya terhadap generasi milenial kemudian menghadirkan potensi untuk menghadirkan sarana dan pra-sarana terkait kegiatan olahraga. Terkhusus di Ibukota Jakarta, kehadiran sarana dan pra-sarana kegiatan olahraga tergolong minim dan cenderung tidak mengikuti perkembangan generasi sehingga dinilai kurang fungsional serta tidak fleksibel. Selain itu, minimnya lahan terbuka yang dapat dimanfaatkan masyarakat untuk melakukan kegiatan olahraga menjadi salah satu factor utama dalam merancang gelanggang remaja.

\section{KAJIAN LITERATUR}

Gelanggang /ge-lang-gang/ $\mathrm{n}$ ruang atau lapangan tempat berolahraga, bertinju, dan sebagainya. Remaja /re-ma-ja/ $\mathrm{n}$ tumbuh atau tumbuh menjadi dewasa,kematangan mental, emosional sosial, dan fisik (Hurlock,192), rentang usia 10-19 tahun (menurut World Health Organization). Maka dapat disimpulkan gelanggang remaja merupakan ruang yang dimanfaatkan untuk kegiatan olahraga bagi seorang yang sedang berada dalam proses pertumbuhan. Gelanggang juga berarti arena atau lingkaran. Olahraga menurut KBBI memiliki arti gerak badan untuk menguatkan dan menyehatkan tubuh. Olahraga juga berarti suatu kesibukan / kegiatan jasmani dan rohani yang dilaksanakan secara teratur dalam segi waktu, alat, dan tempat, secara spontan dan swadaya serta mencakup segala kegiatan kehidupan manusia untuh memperkuat daya tahan tubuh dan membentuk kepribadian. Dapat disimpulkan gelanggang olahraga berarti arena atau tempat untuk menyehatkan fisik dan pikiran.

Gelanggang remaja atau Youth Centre di dalam bahasa Inggris mengandung pengertian yaitu suatu arena atau tempat bertanding. Dengan demikian Gelanggang Remaja memiliki pengertian tempat bertanding atau berkompetisi para remaja dalam berbagai macam kegiatan. Sehubungan dengan itu maka Gelanggang Remaja juga dapat dipahami sebagai suatu arena atau tempat yang bersifat tetap bagi para remaja untuk menyelenggarakan berbagai macam kegiatan secara teratur dan terarah dengan penanggung jawab tertentu. Di dalam gelanggang mereka dapat berekreasi dan berkreasi sesuai dengan aspirasi, hasrat, bakat dan niatnya serta dapat menggunakan fasilitasi yang tersedia di tempat. Sehingga arena ini bermaksud memberikan fasilitas bagi penyaluran dan pengembangan aspirasi, hasrat dan minat yang kreatif dimana penyelenggaraannya berlandaskan pada unsur-unsur pendidikan dan rekreasi.

\section{METODE}

Metode perancangan yang digunakan adalah :

- Studi literatur

- Sebagai dasar dalam pembentukan konsep perancangan

- Mengetahui standar terkait program yang akan direncanakan

- Studi preseden

- Sebagai komparasi dengan proyek

- Mempelajari perkembangan fungsi proyek serupa

- Pengamatan lingkungan

- Lokasi : Jl. Tanjung Duren Barat III \& IV, JI. Lontar Raya, Jl. Tanjung Duren Raya

- Waktu : 09.00 - 16.00, pagi hingga sore hari. 
- Metode pengamatan

- Survey lapangan

- Pengambilan foto sekitar

- Metode perancangan arsitektur

\section{Tipologi}

Kajian tentang tipe, tipe sendiri dalam bahasa Yunani berarti tupos yang berarti tanda atau suatu kesan yang ditimbulkan oleh cambutan (keras). Kata tersebut dalam bentuk Latin Akhir berarti suatu sosok, atau suatu pola berulang dari suatu penyakit.

Dalam arsitektur barat, kajian tentang tipe ini menjadi suatu andalan para mahasiswa arsitektur untuk menyelesaikan perancangan. Namun penggunaan tipe ini menyurut dengan kebangkitan gerakan modern dalam arsitektur yag mengandalkan program. Isu mengenai tipologi muncul kembali berkat gugatan Maldonado yang berkilah bahwa pada saat penyeleksian arsitektural yang berdasarkan program mengalami kesulitan karena tidak semua kegiatan dapat diamati dengan rinci, maka tipologi bentuk arsitektur dapat membantu menyelesaikan $\mathrm{m}$ asalah.

Arsitektur tipologi diamati oleh beberapa arsitek, pertama dilihat bahwa arsitektur lahir dari arsitektur vernakular primitif, yang kedua adalah tidak mengandalkan bentuk tetapi mengandalkan proses yang diusulkan oleh Le Corbusier dan tipologi arsitektur ke 3 di pelopori oleh kaum Neo-Rasionalis yaitu kota sebagai tapak arsitektur. Aldo Rossi mengaitkan ekologi dan psikologi dalam satu bidang untuk pemahaman gejala arsitektur.

a. Analisis Tipologi Bangunan

Dalam kajian tipologis,sebuah objek arsitektur yang hadir perlu diperhatikan dari unsurunsur pembentuknya. Kumpulan hal tersebut adalah denah. Setiap reduksi unsur perlu dianalisis dan melihat ranah yang terbentuk olehnya dan hubungan antar ranah.

b. Tipologi Ruang Kegiatan

Kegiatan manusia ada yang bersifat mendasar, berhubungan dengan badan dan kontemplasi semuanya berkonsekuensi terhadap penilaian ruang dan syarat yang dihasilkan. Dalam membatasi batas ruang gerak kita sering mengaitkan nama ruang dengan kegiatan namun nama tidak menggambarkan tipe melainkan model dan hal itu perlu dikaji lagi.

c. Tipologi Ruang Formal

Ruang tersebut berbatasan dengan sesuatu yang mengidentifikasi bentuk ruangan tersebut. Mempelajari tipe formal adalah mengkhayati kemungkinan dari apa yang terkandung di balik kata-kata keterangan yang selalu tidak sepenuhnya. Bila perancang mengacu pada tipe maka lebih bebas menentukan sesuatu keadaan di dalam konteks.

d. Penggunaan

Dalam penggunaannya ruang kegiatan tidak dapat dibedabedakan dari tipe ruang formal. Kegiatan menghasilkan corak yang perlu dikaitkan dengan bentuk konkritnya.Melalui denah, pergerakan melahirkan jenis gerakan menuju arah tertentu dan fokus. 


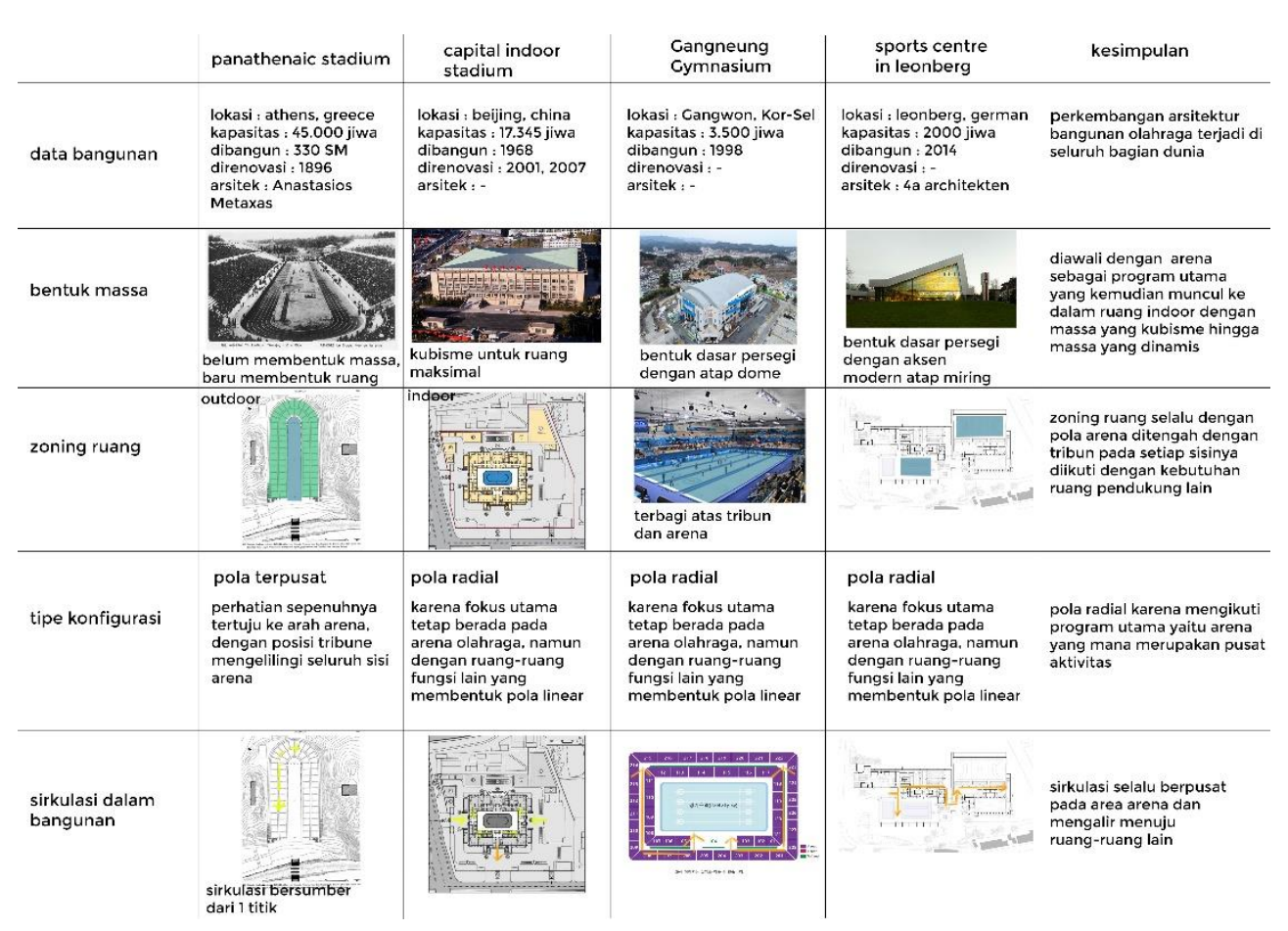

Gambar 1. Perkembangan bangunan olahraga

Sumber: Penulis, 2019

\section{DISKUSI DAN HASIL \\ Program}

Program berdasarkan kepada tujuan utama proyek yaitu menghadirkan fasilitas olahraga yang dapat memenuhi kebutuhan masyarakat akan ruang public, serta didukung dengan analisa aktivitas kawasan. Dengan mewadahi kebutuhan masyarakat akan ruang untuk berolahraga, masyarakat diajak untuk berolahraga secara tidak langsung dengan kehadiran tangga sebagai sirkulasi utama menuju dan di dalam bangunan. Maka, masyarakat yang datang dengan tujuan tidak berolahraga pun secara tidak langsung telah melakukan aktivitas olahraga dengan menaiki tangga-tangga yang berada di dalam bangunan yang bersifat public ini.

Aktivitas olahraga terbagi menjadi 2 area yaitu indoor dan outdoor, olahraga futsal dan area skateboard berada pada sisi outdoor bangunan, yang berbatasan langsung dengan fungsi bangunan eksisting berupa sekolah karena olahraga tersebut merupakan olahraga yang digandrungi oleh remaja khususnya pelajar sekolah sehingga dapat dimanfaatkan langsung bagi masyarakat terkhusus pelajar sekolah. Sedangkan untuk area olahraga indoor dimanfaatkan sebagai lapangan olhraga basket, voli, dan badminton, serta olahraga berbasis indoor lainnya. Olahraga indoor lainnya terdiri atas olahraga meja yaitu billiard dan olahraga berbasis elektronik (esports), fasilitas esports yang dihadirkan sifatnya berupa komunitas sehingga memiliki kapasitas tertentu. Selain itu olahraga indoor juga terdiri atas jogging track yang berada berdampingan dengan ruang gym dan interactive pool yang bertujuan sebagai wahana interaksi bagi user bangunan, pada sisi kolam kemudian dimanfaatkan sebagai communal space berupa area duduk bagi user bangunan. Kemudian fasilitas pendukung hadir sebagai bentuk pemenuhan kebutuhan masyarakat, terdapat ruang serbaguna yang dapat dimanfaatkan oleh masyarakat, musholla dihadirkan untuk memenuhi kebutuhan masyarakat untuk beribadah. 


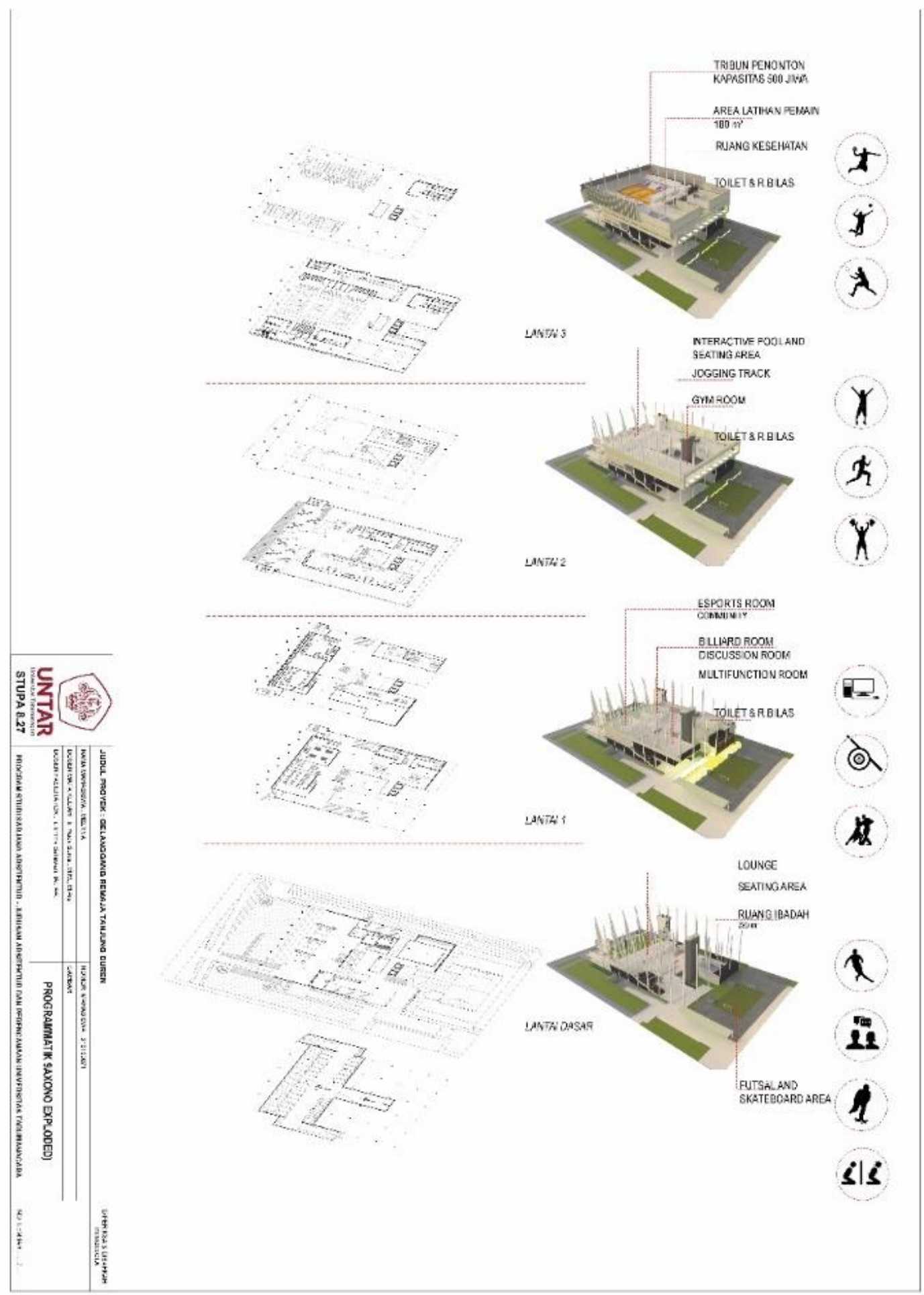

Gambar 2. Programmatik

Sumber: Penulis, 2019 


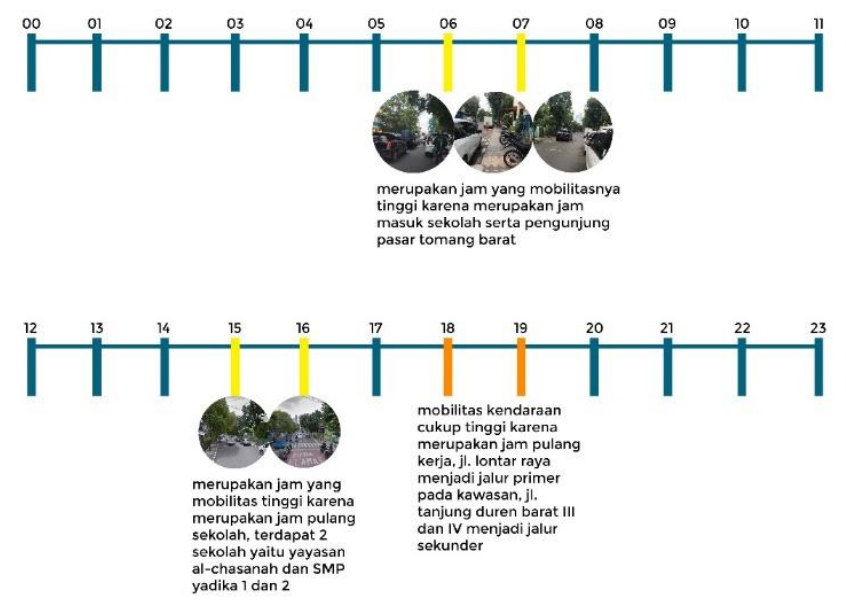

Gambar 3. Skema aktivitas lingkungan

Sumber: Penulis, 2019

\section{Tapak}

Lokasi tapak berada di Jakarta bagian Barat, Kecamatan Grogol Petamburan, Kelurahan Tanjung Duren Utara. Secara mikro lokasi tapak berada di antara JI. Tanjung Duren Barat III dan JI. Tanjung Duren Barat IV. Pada sisi timur tapak berbatasan langsung dengan SMA Yadika I \& II yang kemudian dimanfaatkan sebagai meeting point daripada siswa sekolah, pada sisi selatan dan utara tapak berseberangan dengan fungsi bangunan berupa pemukiman, sedangkan pada sisi barat tapak berbatasan langsung dengan Jl. Lontar Raya dengan lebar jalan $12 \mathrm{~m}$. Tapak dikelilingi oleh bangunan dengan fungsi pemukiman, toko barang dan jasa, kantor pemerintahan, dan fasilitas pendidikan. Tapak berada di lokasi strategis karena terdapat titiktitik halte bus dengan jarak $<500 \mathrm{~m}$ dari tapak, sehingga memudahkan pencapaian menuju tapak. Pedestrian eksisting pun berada dalam kondisi yang memadai serta berada dalam jarak nyaman pejalan kaki $(400 \mathrm{~m})$ yang berasal dari halte bus. Tapak terpilih akan dimanfaatkan untuk merancang fasilitas umum dan sosial yang diharapkan dapat menjadi standar bagi fasilitas pemerintah di kecamatan lain. Berikut merupakan profil tapak ;

Luas tapak : $10.800 \mathrm{~m}^{2}$

Peruntukan : zona pelayanan umum dan sosial

$\begin{array}{llll}\text { KDB } & : 40 & -> & 4.320 \mathrm{~m}^{2} \\ \text { KLB } & : 1.6 & -> & 17.280 \mathrm{~m}^{2} \\ \text { KTB } & : 55 & -> & 5.940 \mathrm{~m}^{2}\end{array}$

KB $\quad: 4$ lantai (dapat dilakukan penambahan jika dibutuhkan)

$\mathrm{KDH}$

$$
\begin{array}{lll}
: 30 \quad \rightarrow & 1.296 \mathrm{~m}^{2}
\end{array}
$$

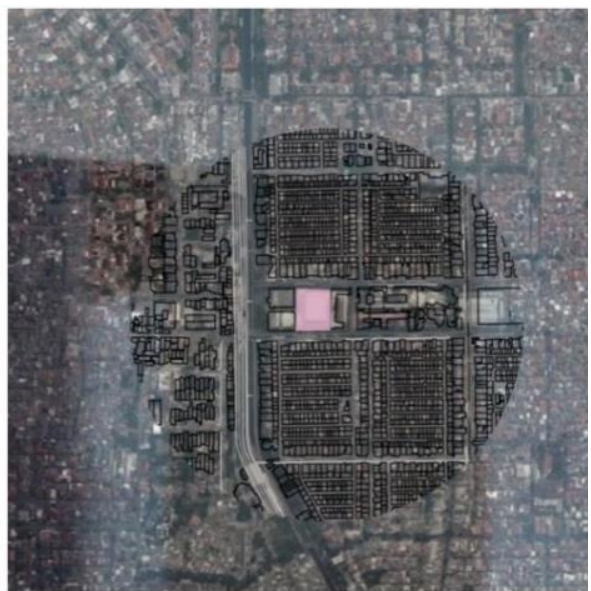

Gambar 4. Posisi tapak terhadap sekitar Sumber : Google Maps, 2019 


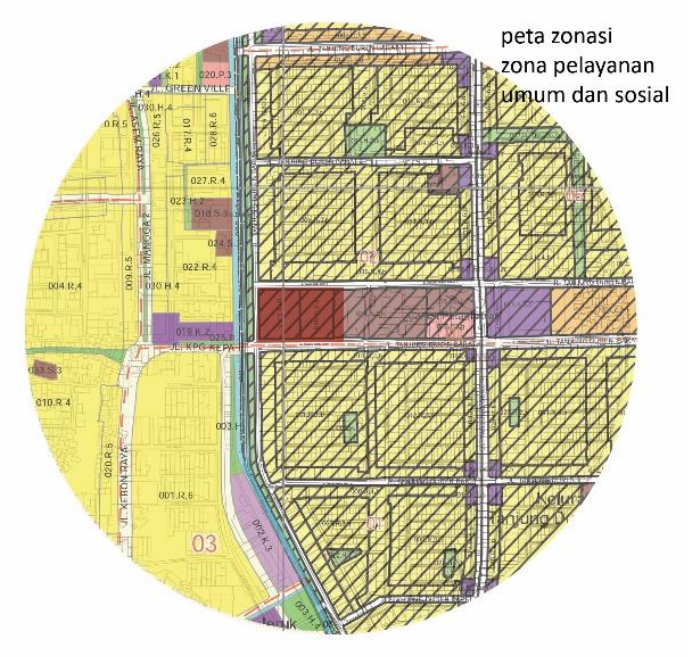

Gambar 5. Posisi tapak terhadap peruntukkan Sumber : Peta zonasi DKI Jakarta, 2014

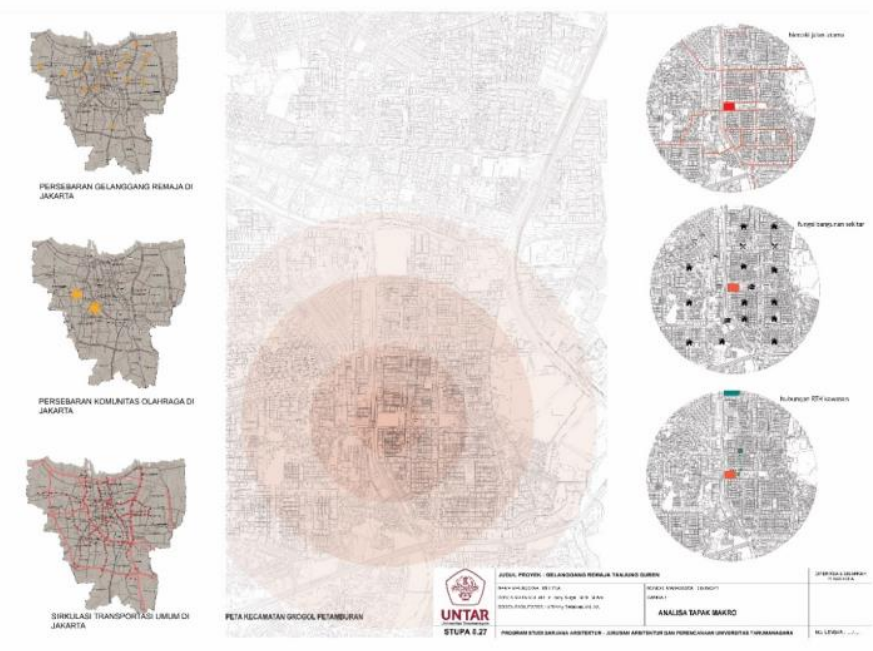

Gambar 6. Analisa tapak kawasan

Sumber: Penulis, 2019

\section{Konsep}

Didasarkan atas lokasi tapak dengan fungsi bangunan sekitar maka, sisi timur yang berbatasan langsung dengan SMA Yadika I \& II dimanfaatkan untuk menghadirkan fasilitas olahraga yang dibutuhkan bagi siswa sekolah yaitu lapangan futsal serta area skateboard, sehingga diharapkan fungsi lapangan terbuka tersebut juga secara tidak langsung dapat menarik minat pelajar sekolah untuk mengunjungi bangunan gelanggang olahraga. Sisi utara dan selatan tapak yang berfungsi sebagai pemukiman padat, dilihat sebagai sebuah potensi untuk meningkatkan aksesibilitas lingkungan yang kemudian diwujudkan ke dalam fisik bangunan dengan menghadirkan entrance menuju tapak pada setiap sisinya. Karena dikelilingi oleh fungsi - fungsi bangunan dengan tingkat mobilitas yang tinggi, maka aksesibilitas kemudian menjadi unsur utama dalam merancang hingga ke dalam program bangunan. Sebagai bangunan berbasis olahraga, pengunjung juga secara tidak langsung diajak untuk berolahraga yaitu dengan menggunakan tangga sebagai sirkulasi utama di dalam bangunan. Tangga utama berada pada sisi utara dan selatan bangunan yang berseberangan dengan fungsi bangunan berupa pemukiman. Sedangkan pada sisi barat, kemudian menjadi entrance utama ke dalam bangunan dengan menjadikan halte bus sebagai pertimbangan. Tepat di seberang sisi barat tapak terdapat sebuah halte bus, yang merupakan moda transportasi utama bagi masyarakat kecamatan Grogol Petamburan. 


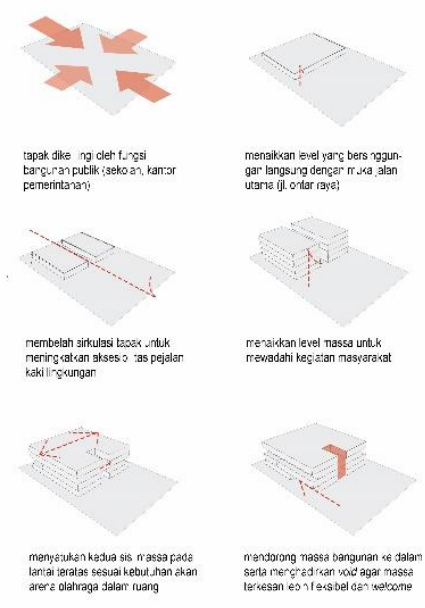

Gambar 7. Skema desain

Sumber: Penulis, 2019

\section{KESIMPULAN}

Menjaga kesehatan merupakan unsur fundamental dalam menjalankan kehidupan seharihari, terutama di jaman sekarang dimana kehidupan kita dipenuhi dengan berbagai macam kesibukan. Berbagai macam resiko penyakit mengancam khususnya generasi milenial yang dinilai kurang menyadari akan pentingnya kesehatan, generasi milenial bahkan dinilai memiliki tingkat kesehatan yang buruk dibandingkan dengan generasi-generasi sebelumnya. Padahal jika ditelaah lagi, generasi milenial telah memiliki kesadaran untuk berolahraga namun kegiatan berolahraga yang konvensional telah dinilai kurang menarik. Pengalaman menjadi kunci bagi generasi milenial dalam menjalankan aktivitas hingga mengambil keputusan.

Olahraga dilakukan karena hobi maupun untuk mencapai sebuah tujuan kesehatan, dalam melakukan kegiatan berolahraga tentunya dibutuhkan sebuah wadah untuk beraktivitas. Gelanggang olahraga merupakan sebuah wadah untuk menampung aktivitas tersebut, dengan cakupan area pelayanannya masing-masing, gelanggang olahraga hadir untuk memenuhi kebutuhan masyarakat akan fasilitas umum dan sosial khususnya pada bidang olahraga.

Pada proyek kali ini dipilih tapak yang berlokasi pada kecamatan Grogol Petamburan, kelurahan Tanjung Duren Utara, karena dinilai berpotensi tinggi baik dari segi peminatan hingga jumlah penduduk khususnya di kelas usia produktif. Dengan berdasarkan kepada kebutuhan masyarakat akan ruang untuk berolahraga, ruang untuk bersosialisasi bagi generasi milenial, ruang terbuka hijau, serta ruang untuk mengembangkan minat dan bakat.

Akan dirancang sebuah gelanggang olahraga yang segala kegiatan pada programya bertujuan untuk meningkatkan kualitas generasi milenial. Dengan menghadirkan fasilitas olahraga indoor seperti lapangan basket, bulu tangkis, voli, dan futsal, serta ruang serbaguna bagi masyarakat yang ingin mengembangkan minat dan bakat dalam bidang seni, juga menghadirkan ruang bagi pelaku komunitas olahraga eSports.

Selain dari program di dalam bangunan, bagian dari tapak terpilih juga akan berkontribusi dalam membentuk kebiasaan masyarakat yang lebih baik. Seperti, meningkatkan konektivitas antara tapak terpilih dengan lingkungan sekitar yang diwujudkan secara fisik melalui hadirnya entrance bangunan pada setiap sisi yang dapat mempersingkat waktu tempuh masyarakat dari satu sisi menuju sisi lain, selain itu juga secara tidak langsung meningkatkan kesehatan masyarakat melalui aktivitas cardio menaiki tangga, dengan menghadirkan tangga sebagai sirkulasi utama baik menuju maupun di dalam bangunan. 


\section{REFERENSI}

Anak, K. P. (2018). Statistik Gender Tematik. Profil Generasi Milenial Indonesia, 46.

Barat, B. P. (2017). Badan Pusat Statistik. Diambil kembali dari jakbarkota.bps.go.id: https://jakbarkota.bps.go.id/publication/download.html?nrbvfeve=NmU5YTBiOWEyNjhhN mRiMmFIZTIOYjQz\&xzmn=aHROcHM6Ly9qYWtiYXJrb3RhLmJwcy5nby5pZC9wdWJsaWNhdG Ivbi8yMDE4LzA4LzE2LzZIOWEwYjlhMjY4YTZkYjJhZWUyNGIOMy9rb3RhLWpha2FydGEtYmFy YXQtZGFsYWOtYW5na2EtMjAxOC5od

Fuadila, N. (2016). Pusat Kreativitas Pemuda. Pusat Kreativitas Pemuda Kwala Bekala, 60-69.

LPMB, Y. (2015, october 27). Indonesia Dokumen. Diambil kembali dari dokumen.tips: https://dokumen.tips/documents/sni-03-3647-1994.html

MPP Global. (2018, Agustus 03). MPP global solutions. Diambil kembali dari mppglobal.com: https://www.mppglobal.com/news/blog/how-are-millennials-changing-the-sportsengagement-landscape/

sports insight. (2018, Maret 10). sports insight. Diambil kembali dari sports-insight.co.uk: https://www.sports-insight.co.uk/trends-features/9-things-you-need-to-know-aboutmillennials

Tjahjono, G. (2000). Metode Perancangan (Suatu Pengantar untuk Arsitek dan Perancang). Jakarta: UI Press.

Windasari, E. (2017, November 29). womantalk. Diambil kembali dari womantalk.com: https://womantalk.com/health/articles/pada-usia-ini-generasi-millennial-merasa-palingstres-di-hidupnya-D6P1g 